\title{
Modulation of human upper gastrointestinal motility by rectal distension
}

\author{
J E KELLOW, R C GILL, AND DAVID L WINGATE \\ From the Gastrointestinal Science Research Unit, London Hospital Medical College, London
}

SUMMARY The effects of rectal distension on upper gastrointestinal motility were investigated in six healthy subjects. On a control day, gastric and duodenal motor activity was recorded for nine hours of fasting and for four hours after a meal, duodeno-caecal transit being assessed in both interdigestive and digestive states. Motor activity and transit were also measured on a test day during which the rectum was distended for one hour during fasting and for one hour postprandially. Control and test days were randomised. During fasting, rectal distension increased the incidence of migrating motor complexes $\left(0.8 \pm 0.3 v 0.5 \pm 0.2 \mathrm{~h}^{-1} ; \mathrm{p}<0.01\right)$ and reduced the duodenal phase 2 motility index to $66 \pm 45 \%$ of that observed on the control day $(\mathrm{p}<0.01)$. Further, duodeno-caecal transit time was increased by rectal distension $(99 \pm 30 v 71 \pm 35 \mathrm{~min} ; \mathrm{p}<0.05)$. Postprandially, the period of rectal distension was marked by a reduction in the duodenal motility index to $24 \pm 13 \%$ of that observed during the comparable period on the control day $(\mathrm{p}<0.001)$ and a concomitant increase in duodeno-caecal transit time $(113 \pm 22 v 80 \pm 17 \mathrm{~min} ; \mathrm{p}<0 \cdot 01)$. We conclude that upper gastrointestinal motor activity, the effector of luminal transit, may be profoundly influenced by stimulation of distal afferents.

In the investigation of patients with functional bowel disorders, disturbances of upper gastrointestinal motility have been shown in association with colorectal dysfunction as manifested by altered patterns of defecation. ${ }^{1-3}$ Although this may reflect a widespread disorder of gastrointestinal smooth muscle, inappropriate activation of enteroenteric reflexes ${ }^{4}$ may also occur. Early animal studies showed that gastric ${ }^{57}$ and small intestinal motor activity ${ }^{67}$ could be inhibited by rectal distension, the rapidity of the response suggesting a predominantly neural mechanism. More recent studies confirm these findings and suggest that both splanchnic and vagal components participate in this reflex. ${ }^{\circ}$

In man, different patterns of gastric and small intestinal motor activity occur during the interdigestive and digestive states. ${ }^{9}$ Throughout fasting, a period of intense regular contractile activity recurs

Address for correspondence: Dr David L Wingate, Gastrointestinal Science Research Unit, 26 Ashficld Strect, London E1 2 AJ.

Received for publication 7 November, 1986 cyclically. This represents the activity front, or phase 3 , of the migrating motor complex (MMC) which propagates caudally from the stomach towards the ileum. The activity front is preceded by a period of irregular contractile activity, referred to as phase 2 , and is followed by a period of motor quiescence, referred to as phase 1 . On feeding, this pattern of cyclic motor activity is abolished and replaced by a pattern of regular gastric, and irregular small intestinal, contractions. We are unaware of any information concerning the modulation of fasting or postprandial patterns of gastrointestinal motor activity by rectal distension in man; this is surprising in view of the recent demonstration that such distension delays gastro-caecal transit of a meal."

The aims of the present study were to investigate the effects of rectal distension on fasting and postprandial patterns of human gastroduodenal motility. In order to assess the functional consequences of any observed alterations in small intestinal motor activity, we also investigated the effects of rectal distension on duodeno-caecal transit. 


\section{Methods}

\section{SUBJECTS}

Six healthy volunteers (four men, two women) with a mean age of $21 \pm 3$ years participated in this study after informed consent was obtained. None had symptoms, or a history, of gastrointestinal disease, nor was any participant taking medication. The experimental protocol for this study was approved by the Ethics Committee of the Tower Hamlets Area Health Authority.

\section{GASTRODUODENAL MANOMETRY}

Intraluminal pressures were recorded from the gastric antrum and from the second and third parts of the duodenum using a multilumen transnasal catheter with recording orifices 1,11 , and $26 \mathrm{~cm}$ from the distal end. The catheter was positioned under fluoroscopic control. Recording orifices were constantly perfused with water at a rate of $0.1 \mathrm{ml} / \mathrm{min}$ using a pneumohydraulic infusion pump (Arndorfer Medical Specialties, Greendale, WI, USA). Pressures were transmitted to external pressure transducers (Gaeltec S8b, Gaeltec Ltd, Skye, Scotland), the output of which was recorded on a polygraph (Graphtec Linearcorder WR 3101, Graphtec Corp, Japan).

\section{DUODENO-CAECAL TRANSIT}

Duodeno-caecal transit time was estimated by measuring the hydrogen concentration in serial 10 minute samples of end-expired air." After the instillation of $7 \mathrm{~g}$ lactulose into the duodenum via the proximal duodenal recording orifice, breath sampling continued for three hours. Hydrogen concentrations were determined with an autoanalyser (Exhaled Hydrogen Monitor, GMI Medical Ltd, Renfrew, Scotland).

RECTAL DISTENSION

A $3 \mathrm{~cm}$ long cylindrical balloon (constructed from $5 \mathrm{~cm}$ of unstretched latex condom) connected to a polyvinyl tube (external diameter $4 \mathrm{~mm}$ ) was positioned in the rectum. The balloon was slowly inflated $(2 \mathrm{ml} / \mathrm{sec})$ with air until the subject expressed a persistent sensation of rectal distension, ${ }^{12}$ the volume and pressure within the balloon being noted. The balloon was maintained at this volume for a period of one hour and then deflated.

BLOOD PRESSURE AND HEART RATE Blood pressure and radial pulse measurements were taken at rest and at 15 minute intervals after inflation of the rectal balloon.
TEST MEAL

A $540 \mathrm{kcal}$ meal consisting of $125 \mathrm{~g}$ roast chicken, 114 g mashed potato, $85 \mathrm{~g}$ peas, $28 \mathrm{~g}$ cheddar cheese and a dessert of $30 \mathrm{~g}$ ice cream was provided on each study day.

EXPERIMENTAL PROTOCOI

Subjects were intubated 12 hours before the start of the recording period. Recordings were made for two consecutive days, with control and test days being randomised. On the control day, gastroduodenal motor activity was recorded for nine hours during fasting and for four hours after the test meal. To assess fasting duodeno-caecal transit, lactulose was instilled 30 minutes after phase 3 of the first duodenal MMC. Postprandial duodeno-caecal transit was assessed by instilling lactulose $\mathbf{3 0}$ minutes after the meal. Motor activity and transit were also measured on the test day, during which the rectum was distended both during fasting and again postprandially, distension starting immediately before lactulose instillation.

\section{DATA ANALYSIS}

Recordings of gastroduodenal motor activity were analysed visually by two independent observers. During fasting, the duration of phases 1, 2, and 3 of the MMC and the MMC cycle length were determined as previously described." A motility index (MI), calculated as the product of the number and mean amplitude of contractions, was determined for each 10 minute period of duodenal phase 2 . The mean 10 minute $\mathrm{MI}$ of each phase 2 (control and test days) was subsequently expressed as a percentage of the mean phase $2 \mathrm{MI}$ of the control day. Postprandially, MIs were also calculated for each 10 minute period of gastric and duodenal activity and expressed as a percentage of the mean 10 minute $\mathrm{MI}$ during the first 30 postprandial minutes.

Duodeno-caecal transit time was defined as the time for the instillation of lactulose into the duodenum until the first sustained rise in breath hydrogen concentration (taken as an increase of $>5 \mathrm{ppm}$ $\mathrm{H}_{2}$ in each of three consecutive samples).

STATISTICAL ANALYSIS

Data presented throughout this study have been expressed as mean $\pm \mathrm{SD}$; statistical significance was assessed using Student's $t$ test for paired data.

\section{Results}

All subjects completed the experimental protocol and none expressed discomfort or distress associated with either the transnasal catheter or rectal distension. The rectum was distended using a balloon 
volume of $224 \pm 43 \mathrm{ml}$, corresponding to a rectal pressure of $34 \pm 9 \mathrm{mmHg}$. Subjects reported that the sensation of rectal distension persisted throughout the period during which the balloon was inflated. No significant changes $(p>0.4)$ in diastolic or systolic blood pressure or in heart rate were observed during the period of rectal distension.

\section{FASTING STUDIES}

\section{Gastroduodenal manometry}

Fasting gastroduodenal motor activity was characterised by the cyclic recurrence of the MMC (Fig. 1). In all subjects, MMC cycle length decreased after rectal distension $(79 \pm 34 v 123 \pm 60 \mathrm{~min} ; \mathrm{p}<0 \cdot 01)$. No phase 3 activity fronts occurred during the period of distension. The proportion of phases 1,2, and 3 of the MMC did not alter after rectal distension (32 \pm 26 , $64 \pm 26$ and $4 \pm 2 \% \quad v 25 \pm 14,71 \pm 14$ and $5 \pm 4 \%$ respectively; $p>0.25$ ) and thus the duration of duodenal phase 2 was reduced $(56 \pm 38 v 79 \pm 43 \mathrm{~min}$; $\mathrm{p}<0.01)$. As contractile amplitude during phase 2 remained constant, the duodenal phase $2 \mathrm{MI}$ was also decreased after rectal distension $(66 \pm 45 v 100 \pm 48 \%$; $\mathrm{p}<0 \cdot 01)$.

\section{Duodeno-caecal transit}

Duodeno-caecal transit time was increased in all subjects after distension of the rectum $(99 \pm 30 v$ $71 \pm 25 \mathrm{~min} ; \mathrm{p}<0 \cdot 05)$. During the time interval between the instillation of lactulose into the duodenum and its subsequent arrival in the caecum, no activity fronts were observed on either control or test days.

\section{POSTPRANDIAL STUDIES}

\section{Gastroduodenal manometry}

In all subjects, the fasting pattern of gastroduodenal motor activity was abolished on eating and typical postprandial motor patterns established. Postprandially, the onset of rectal distension was marked by an immediate and striking inhibition of gastric and duodenal contractions (Fig. 2). This inhibition of gastroduodenal contractile activity continued throughout the period of rectal distension, with a significant decrease $(p<0.001)$ in the duodenal MI (Fig. 3). Postprandial gastric and duodenal motor patterns were rapidly re-established after deflation of the rectal balloon. Detailed analysis of postprandial gastric activity was limited as postprandial gastric contractions were recorded in only three of the subjects; a similar inability to record these contractions has been reported by others and is a recognised limitation of manometry. ${ }^{13} 14$

\section{Duodeno-caecal transit}

Duodeno-caecal transit time was increased in all subjects after distension of the rectum $(113 \pm 22 v$ $80 \pm 17 \min ; \mathrm{p}<0 \cdot 01)$.

\section{Discussion}

Distension of the rectum is a normal occurrence, representing the primary stimulus for initiation of the defaecatory reflex. ${ }^{15}$ In the present study, the rectum was not distended sufficiently to elicit an uncontrollable urge to defecate but, rather, to provide persistent awareness of rectal sensation. ${ }^{12}$ This was not stressful; subjects denied that the stimulus was unpleasant or distressing and, in contrast with the findings of studies in which various other psychological ${ }^{16}$ or painful ${ }^{17}$ stimuli have been applied, no cardiovascular response was elicited.

In all fasting subjects, an increased incidence of MMCs in the gastroduodenum was observed after rectal distension. The mechanisms controlling the MMC are poorly understood, although it is clear that both neural and humoral factors are involved. ${ }^{18}$ It has been proposed that the periodicity of the MMC is governed by an extra-enteric clock, ${ }^{19}$ while recent studies in the dog have shown that the occurrence of
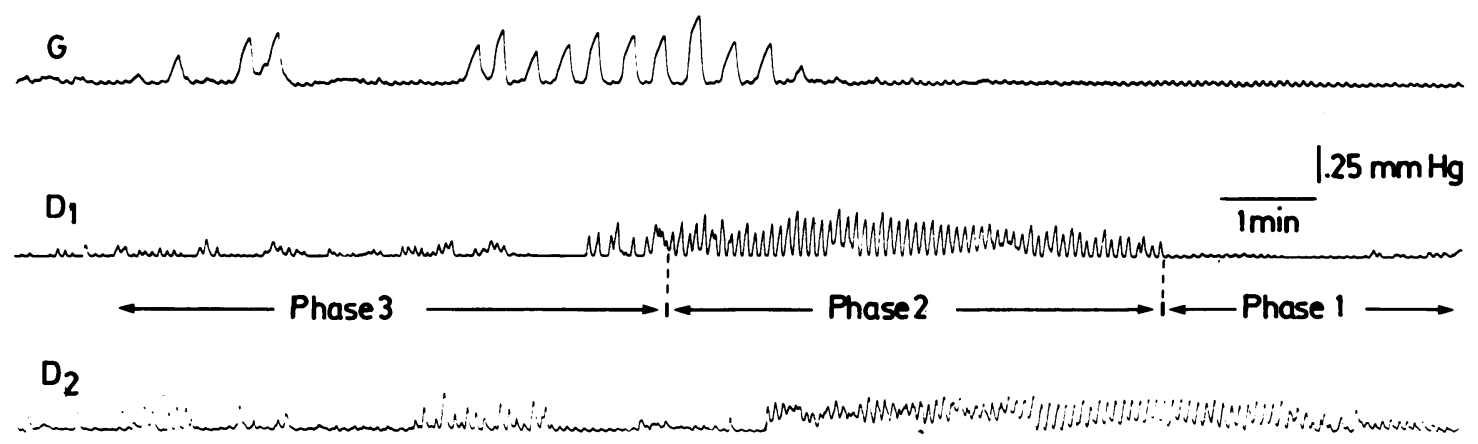

Fig. 1 Manometric recording showing migrating motor complex (MMC) in the gastric antrum $(G)$ and two sites in the duodenum $\left(D_{1}, D_{2}\right)$ of a healthy subject; phases 1,2 , and 3 of the MMC are indicated. 
(a)

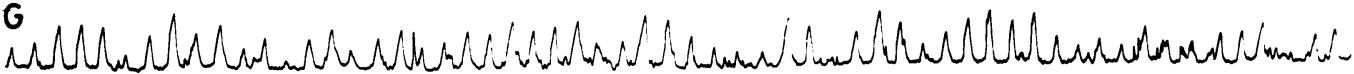

$D_{1}$

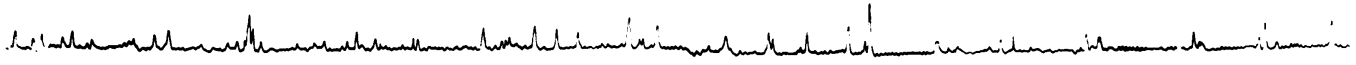

$D_{2} \quad \frac{1}{125 \mathrm{~mm} H \mathrm{~g}}$

$1 \mathrm{~min}$

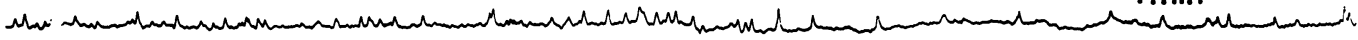

(b)

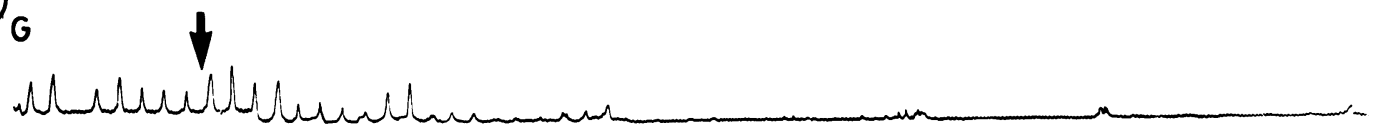

D

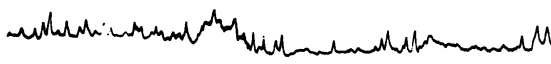

$\mathrm{D}_{2}$

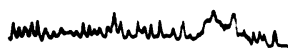
$N$

Fig. 2 Manometric recording showing postprandial gastric $(G)$ and duodenal $\left(D_{1}, D_{2}\right)$ motor activity 30 min after a standard meal in a healthy subject on the control day (a). During the comparable period on the test day (b), postprandial motor activity was inhibited upon distension of the rectum (arrow shows onset of inflation of rectal balloon).

the MMC, at least in the upper gastrointestinal tract, is dependent on vagal integrity. ${ }^{20}$ Rectal distension excites serosal mechanoreceptors, and probably mucosal touch receptors, in the anorectum. The resultant change in afferent neural discharge must be signalled centrally as rectal stimulation is consciously perceived. ${ }^{15}$ It is therefore possible that distension of the rectum may modulate the efferent vagal discharge upon which the fasting pattern of gastroduodenal motility depends. ${ }^{20}$ Phase 2 of the MMC, which is also dependent upon activation of the central nervous system, ${ }^{9}$ was also inhibited after the period of rectal distension. Our observation that fasting gastroduodenal motor patterns were affected for several hours after stimulation of the rectum does not exclude the possibility that humoral, as well as neural, components may participate in this response. ${ }^{?}$

With regard to intestinal transit during fasting, this was delayed after rectal distension. No activity fronts originated in the gastroduodenum during the measured duodeno-caecal transit time, however, luminal transit was thus effected by phase 2 of the MMC as previously suggested. ${ }^{21} 22$ Rectal distension resulted in a similar delay in postprandial duodenocaecal transit, a finding confirming that of others, ${ }^{10}$ and most likely caused by inhibition of small intestinal contractions. Furthermore, the con- comitant inhibition of postprandial gastric contractions might account for the delay in gastric emptying observed during prolonged intermittent rectal distension. ${ }^{10}$ Studies in animals have shown similar recto-gastric $^{5-7}$ and recto-intestinal ${ }^{67}$ reflexes, the efferent limb of which appeared to be vagal.

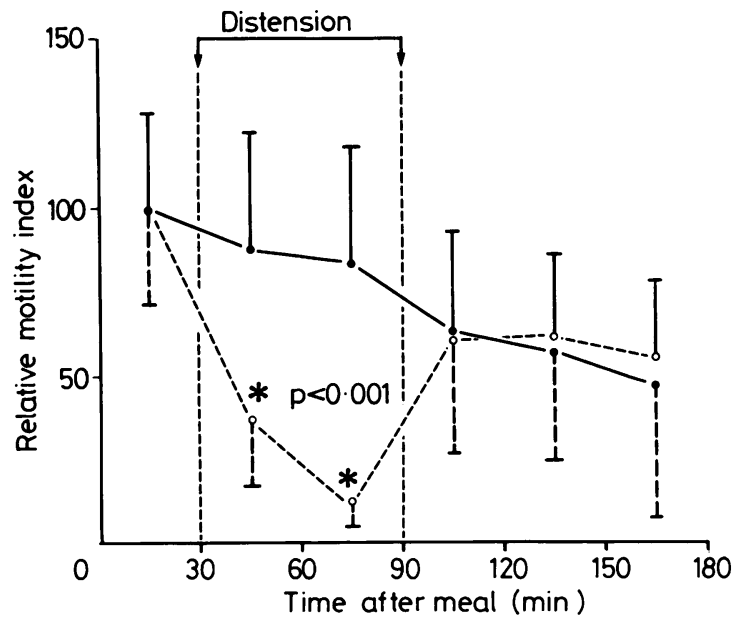

Fig. 3 Postprandial duodenal motility indices (mean $\pm S D$ ) in six healthy subjects on a control day (closed circles) and on a test day (open circles). On the test day, a one hour period of rectal distension commenced 30 min after the meal. 
There is thus increasing evidence that perturbations in one region of the gastrointestinal tract can influence the motor activity and function of more remote regions. Such reflex modulation of gastrointestinal motility establishes many loci at which abnormalities might develop and thus affect function in the entire gastrointestinal tract. In this context, altered sensitivity of peripheral, ${ }^{2324}$ or central receptors, or inappropriate activation of efferent pathways by higher centres ${ }^{25}$ could all affect gastrointestinal motor activity. These factors may play a role in the pathogenesis of the small intestinal motor disorders reported in irritable bowel syndrome. ${ }^{23}$ Our data also provide evidence in support of the concept that generalised, rather than localised, disorders of gastrointestinal function may feature in functional or neuropathic bowel disorders. ${ }^{26}$

\section{References}

1 Malagelada J-R, Stanghellini V. Manometric evaluation of functional upper gut syndrome. Gastroenterology 1985; 88: 1223-31.

2 Kumar D, Wingate DL. The irritable bowel syndrome: a paroxysmal motor disorder. Lancet 1985; ii: 973-7.

3 Kellow JE, Phillips SF. Altered small bowel motility correlates with symptoms in irritable bowel syndrome. Gastroenterology 1986; 90: 1488.

4 Roman C, Gonella J. Extrinsic control of digestive tract motility. In: Johnson LR, ed. Physiology of the gastrointestinal tract. New York: Raven Press, 1981: 289-333.

5 Lalich J, Meek WJ, Herrin RC. Reflex pathways concerned in inhibition of hunger contractions by intestinal distension. Am J Physiol 1936; 115: 410-4

6 Pearcy JF, Van Liere EJ. Studies on the visceral nervous system XVII. Reflexes from the colon. Am J Physiol 1926; 78: 64-73.

7 Youmans WB, Meek WJ. Reflex and humoral gastrointestinal inhibition in unanesthetized dogs during rectal stimulation. Am J Physiol 1937; 120: 750-7.

8 Grundy D, Scratcherd T. A splanchno-vagal component of the inhibition of gastric motility by distension of the intestines. In: Weinbeck M, ed. Motility of the digestive tract. New York: Raven Press, 1982: 39-43.

9 Kellow JE, Borody TJ, Phillips SF, Tucker RL, Haddad AC. Human interdigestive motility: variations in patterns from esophagus to colon. Gastroenterology 1986; 91 : 386-95.

10 Youle MS, Read NW. Effect of painless rectal disten- sion on gastrointestinal transit of solid meal. Dig Dis Sci 1984; 29: 902-6.

11 Corbett CL, Thomas S, Read NW, et al. Electrochemical detector for breath hydrogen determination: measurement of small bowel transit time in normal subjects and patients with the irritable bowel syndrome. Gut 1981; 10: 836-40.

12 Farthing MJG, Lennard-Jones JE. Sensibility of the rectum to distension and the anorectal distension reflex in ulcerative colitis. Gut 1978; 19: 64-9.

13 Hall KE, El-Sharkawy TY, Diamant NE. Vagal control of canine postprandial gastrointestinal motility. Am J Physiol 1986; 250: G501-10.

14 Dent J, Dodds WJ, Sekiguchi T, Hogan WJ, Arndorfer RC. Interdigestive phasic contractions of the human lower esophageal sphincter. Gastroenterology 1983; 84: 453-60.

15 Christensen J. Motility of the colon. In: Johnson LR, ed. Physiology of the gastrointestinal tract. New York: Raven Press, 1981: 445-71.

16 Cann PA, Read NW, Cammack J. Psychological stress and the passage of a standard meal through the stomach and small intestine in man. Gut 1983; 24: 236-40.

17 Thompson DG, Richelson E, Malagelada J-R. Perturbation of upper gastrointestinal function by cold stress. Gut 1983; 24: 277-83.

18 Wingate DL. Backwards and forwards with the migrating motor complex. Dig Dis Sci 1981; 26: 641-66.

19 Wingate DL. The eupeptide system: a general theory of gastrointestinal hormones. Lancet 1976; i: 529-32.

20 Hall KE, El-Sharkawy TY, NE Diamant. Vagal control of migrating motor complex in the dog. Am J Physiol 1982; 243: G276-84.

21 Summers RW, Helm J, Christensen J. Intestinal propulsion in the dog. Gastroenterology 1976; 70: 753-8.

22 Kerlin P, Zinsmeister A, Phillips S. Relationship of motility to flow of contents in the human small intestine. Gastroenterology 1982; 82: 701-6.

23 Ritchie J. Pain from distension of the pelvic colon by inflating a balloon in the irritable colon syndrome. Gut 1973; 14: 125-32.

24 Kellow JE, Miller LJ, Zinsmeister A, Phillips S. Dysmotility of the ileum provoked by stimuli in irritable bowel syndrome. Gastroenterology 1986; 90: 1489.

25 Whitehead WE, Schuster MM. Irritable bowel syndrome: physiological and psychological mechanisms. In: Gastrointestinal disorders. Behavioural and physiological basis for treatment. New York: Academic Press, 1985.

26 Clouse RE, Eckert TC. Gastrointestinal symptoms of patients with esophageal contraction abnormalities. Dig Dis Sci 1986; 31: 236-40. 